\title{
Determining the Effects of LMS Learning Behaviors on Academic Achievement in a Learning Analytic Perspective
}

\author{
Mehmet Firat \\ Anadolu University, Open Education Faculty, \\ Department of Distance Education, Eskişehir, Turkey \\ mfirat@anadolu.edu.tr
}

\begin{abstract}
Two of the most important outcomes of learning analytics are predicting students' learning and providing effective feedback. Learning Management Systems (LMS), which are widely used to support online and face-to-face learning, provide extensive research opportunities with detailed records of background data regarding users' behaviors. The purpose of this study was to investigate the effects of undergraduate students' LMS learning behaviors on their academic achievements. In line with this purpose, the participating students' online learning behaviors in LMS were examined by using learning analytics for 14 weeks, and the relationship between students' behaviors and their academic achievements was analyzed, followed by an analysis of their views about the influence of LMS on their academic achievement. The present study, in which quantitative and qualitative data were collected, was carried out with the explanatory mixed method. A total of 71 undergraduate students participated in the study. The results revealed that the students used LMSs as a support to face-to-face education more intensively on course days (at the beginning of the related lessons and at nights on course days) and that they activated the content elements the most. Lastly, almost all the students agreed that LMSs helped increase their academic achievement only when LMSs included such features as effectiveness, interaction, reinforcement, attractive design, social media support, and accessibility.
\end{abstract}

Keywords: LMS, Learning Analytics, Online Learning, Academic Achievement

\section{Introduction}

Multimedia and hypermedia supported e-learning environments have active, non-linear, and flexible structure. This flexibility has caused a certain level of complexity at the same time. The spread of instructional processes in these complex e-learning environments has increased the need

Material published as part of this publication, either on-line or in print, is copyrighted by the Informing Science Institute. Permission to make digital or paper copy of part or all of these works for personal or classroom use is granted without fee provided that the copies are not made or distributed for profit or commercial advantage AND that copies 1) bear this notice in full and 2) give the full citation on the first page. It is permissible to abstract these works so long as credit is given. To copy in all other cases or to republish or to post on a server or to redistribute to lists requires specific permission and payment of a fee. Contact Publisher@InformingScience.org to request redistribution permission. for content management. This need has resulted in the creation of a number of learning management and content management applications with overlapping features. As a result, such nested concepts with no clear-cut boundaries as Content Management Systems (CMS), Learning Management Systems (LMS) and Learning Content Management Systems (LCMS) have appeared. However, in the present study, Learning 
Management System (LMS), considered to be a more comprehensive concept, is used as an umbrella concept. Learning management systems (LMS) have been proven to encourage a constructive approach to knowledge acquisition and to support active learning (Emelyanova \& Voronina, 2014).

In the last years, learning platforms like Edmodo (Holland \& Muilenburg, 2011), MOOC platforms like EdX and Coursera (Breslow, Pritchard, DeBoer, Stump, Ho, \& Seaton, 2013) and cloud file hosting services like Google Drive and DropBox (Stantchev, Colomo-Palacios, SotoAcosta ,\& Misra, 2014) have become very popular. Similarly, the number of educational mobile applications has been rapidly increasing. The increasing number of Internet-based learning platforms has led to a decreased use of package platforms like CMS and LMS. In addition, CMSs and LMSs, which are still widely used, include Adobe Connect, Blackboard, WebCT and Moodle. Use of LMS provides students and lecturers with a set of tools to improve the learning process and its management (Stantchev et al., 2014). According to Emelyanova and Voronina (2014), as a group of consistent users, teacher and student perceptions of LMS could help determine the probable problems with LMS and create productive learning environments. However, there are limited research in related literature which examine the effects of learner behaviors in LMSs on their academic achievement.

\section{Learning Analytics of LMS}

The use of electronic environments and tools in scientific studies has always been limited to such package programs as online questionnaires, e-mails, SPSS, Nvivo , and LISREL because the collection, interpretation, evaluation, and visualization of electronic data records required specialization until a few years ago. However, today, with the help of various graphs, tables, and other visuals these data can be easily processed and used by students, teachers and analysts (Shum, Knight \& Littleton, 2012).

Learning analytics is an emerging and promising field for IT-supported learning (Conde \& Hernández-García, 2015). Learning analytics is defined as an area which focuses on reaching patterns or tendencies via data sets related to students or via large sets of educational data to maintain the development of supplementary and personalized higher education systems (Johnson, Adams Becker, Estrada, \& Freeman, 2014). Learning analytics is defined by Agudo-Peregrina, IglesiasPradas, Conde-González, and Hernández-García, (2014) as the analysis of electronic learning data allowing teachers, course designers and virtual learning environment administrators to investigate the unobservable patterns and the information underlying the learning process. According to another definition, learning analytics is defined as a developing field in which advanced data analysis tools are used to improve learning and education (Elias, 2011). Lastly, Siemens (2013) defines learning analytics as a new discipline which involves the measurement, collection, analysis, and reporting of data regarding learners and learning contexts to understand and improve the learning itself and the environments in which learning occurs.

The analysis dashboards of Content Management Systems (CMS) and Learning Management Systems (LMS) like Blackboard, Moodle, Edmodo and ConnectEdu are among the major environments in which effective research can be conducted in the field of learning analytics. In LMS systems, users' behavior data are recorded as background data (Macfadyen \& Dawson, 2010). Commonly used by various educational institutions including universities, these environments feature detailed analysis dashboards tracking learner interactions with content, teacher and other learners. As a result of studies to be conducted with the help of these data, problematic aspects of the course can be identified and student learning can be evaluated. 


\section{Literature Review}

Since learning analytics is a new field, related literature is also new. Structuring the field started with the definition studies as in all emerging areas. According to Elias (2011), learning analytics is closely tied to fields such as Web analytics, academic analytics, educational data mining, action analytics, and business intelligence (entire processes of taking strategic decision for the institution utilizing data analyses or algorithms). The rest of the related literature regarding learning analytics mostly focuses on evaluating the learning process (Blikstein, 2011), making learning predictions (Arnold \& Pistilli, 2012), and providing feedback (Jo, Yu, Lee, \& Kim, 2015).

In an experimental study carried out by Agudo-Peregrina et al. (2014), three different interaction classifications were done independently of the system. The study investigated the effects of these classifications in different virtual learning environment formats on academic achievement. The data collected via six completely online VLEs (138 students) and two VLEs (218 students) as face-to-face education support were used. The findings demonstrated that the student-student, student-content, student-system, and student-teacher interactions had significant influence on academic achievement in online courses yet did not have any influence in programs in which VLE was used to support face-to-face education (F2F).

A study was conducted by Emelyanova and Voronina (2014) at Russian National Research University not only to examine the participants' purpose, readiness, and efficacies in using LMS but also to determine the perceptions regarding the effectiveness, usability, and ease of LMS use. The results revealed that, although the teacher and the students did not experience any problems regarding computer and LMS use, the students did not find LMSs useful as a learning tool. The teacher and the students agreed that LMSs acted as storage for course materials. Additionally, it was found that the students did not consider LMSs to be useful for online tasks and communication activities and they preferred face-to-face learning.

Another study was carried out by Castaño-Muñoz, Duart, and Sancho-Vinuesa (2014) using a semi-experimental research design with 9044 students from two Catalan universities. The results revealed that the time spent in an online learning environment alone did not increase learning achievement and interactive learning increased learning achievement.

In their predictive model research Jo et al. (2015) attempted to determine the significant components of learning analytics that support the learning achievement of students. The study was carried out with 41 undergraduate students in a South Korean university. The research findings obtained via a seven-predictor model revealed that $99.3 \%$ of the variance regarding the students' final grades was explained. Total login to LMS, (ir)regularity of learning interval in LMS, and total assignments and assessment composites had a significant correlation with the final grades. Total study time in LMS, interactions with content, interactions with peers, and interactions with instructor did not predict the final grades.

According to Gašević, Dawson, and Siemens, (2015) making predictions regarding student learning and providing effective feedback can be considered to be the two most important outcomes of learning analytics. However, while LMSs have the potential to offer rich learning analytics data, there is limited research on LMSs that are used to support face-to-face education. In addition, as mentioned by Agudo-Peregrina et al. (2014), although the most basic learning data unit for learning analytics in virtual learning environments is interaction, there is no consensus on the type of interactions that lead to effective learning.

There are several studies in the relevant literature examining the effects of LMS use as support material in education on students' achievement, motivation, and engagement in class. However, some of these studies are based only on electronic data and some on students' self-descriptions using traditional data collection tools and methods. In this respect, there is limited research that 
uses learning analytics to study the effect of LMSs as a support material on academic achievement, supporting it with traditional self-description method. Therefore, the present study aims to fill this gap in the related literature.

\section{Method}

The present study was carried out with the explanatory mixed method, which allows collection of quantitative and qualitative data together. According to Creswell (2008), the basic assumption underlying the mixed method research design is that combined use of qualitative and quantitative research methods helps grasp the research problem better than the separate use of these methods does. In explanatory mixed method studies, quantitative data are collected first, and then qualitative data are collected to explain the previously collected quantitative data (Creswell \& Plano Clark, 2011). In the present study, the quantitative data were collected via Blackboard Analytics and GPA (Grade Point Average) scores. Next, the students' views regarding how LMS influenced their academic achievement were determined.

\section{Participants}

A total of 71 third-year students taking the course of BTÖ311 Operating Systems in the department of Computer Education and Instructional Technologies at the Education Faculty of Anadolu University in the Fall Term of the academic year of 2014-2015 took part in the study. Informed consent was obtained from all individual participants by written forms. Although there were 74 students taking the course in question, three students were excluded from the data analysis process due to their absenteeism in the course. 25 of the participants are female, and 46 are male.

\section{Data Collection Process}

Within the scope of the study, three different strategies were applied to collect the research data. For the first strategy, the Blackboard launched as support for the face-to-face Operating Systems course was used. Parallel to face-to-face education, the students' LMS behaviors for 14 weeks were examined via Blackboard analytics. The LMS was used only as a support environment during the course. In the LMS, the content studied mostly before and after the lessons by the students was shared. As the second data collection strategy, students' GPA scores for the face-to-face course were used. After the quantitative data were analyzed, via the related Facebook group, the students were asked the following question: "Do you think Learning Management Systems like Blackboard used as a support environment during lessons influence academic achievement?"

\section{Analysis of Data}

The data were collected both quantitatively and qualitatively. For the analysis of the data, the descriptive statistics of $\%, \mathrm{f}, \mathrm{Sd}, \mathrm{N}$, and $\overline{\mathrm{X}}$, the parametric tests of independent samples t-test, and the Pearson correlation coefficient were used. Correlation coefficient is regarded as the coefficient that refers to the size and direction of the relationship between independent variables. This coefficient ranges between $(-1)$ and $(+1)$. Since correlation coefficients cannot reveal the causal relationship between variables, linear regression analysis was applied. In the study, the data collected from 71 participants were analyzed and visualized with MS Excel and SPSS programs.

Qualitative data including direct quotations were analyzed through content analysis. In this method developed by Osgood, Suci, and Tannenbaum (1957), the direction (for or against) and intensity (level of for or against) of participants' attitudes towards a subject are determined. The evaluators transcribed and coded the data as per content analysis. The process of coding qualitative data and theme extraction coding and themes was run in parallel with the two doctorate academicians. Finally, the findings obtained via the analysis of the data were interpreted. 


\section{Results}

In this section, the findings obtained in the study are presented under related headings as "Descriptive Statistics of the Course," "Relationship between Online Learning Behaviors and Academic Achievement," and "Students' Views about the Effects of LMSs on Academic Achievement." The first two subtitles are related to quantitative results while the final subtitle is related to qualitative results.

\section{Descriptive Statistics of the Course}

The total time spent by the students on course LMS was 11437 minutes. The total time per user was 161 minutes. Figure 1 represents the average time the students spent on LMS according to the days of the week.

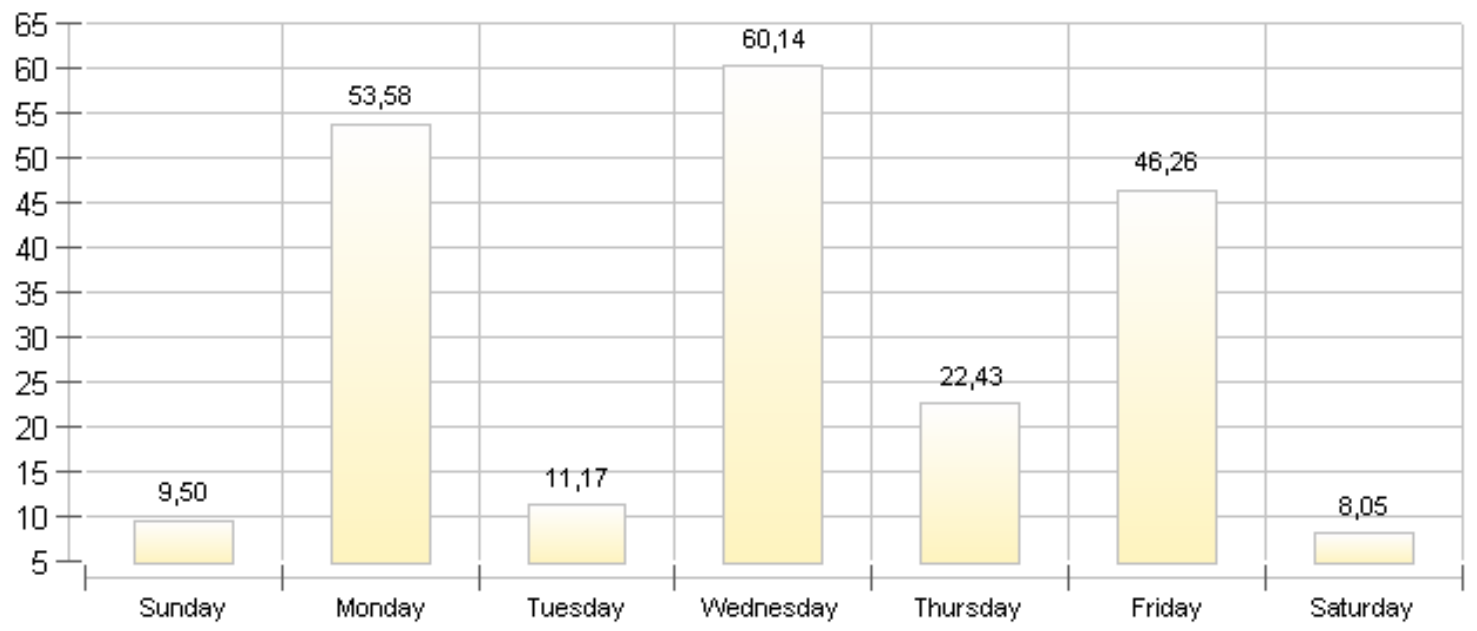

Figure 1: Time spent on LMS with respect to days of the week

When Figure 1 is examined, it is seen that the students spent time on LMS mostly on Monday, Wednesday, and Friday, which are the days on which students attended the face-to-face class. This finding revealed that the students spent time in the LMS on the days of face-to-face class. Figure 2 below demonstrates the time spent by the students in the LMS according to the time of the day.

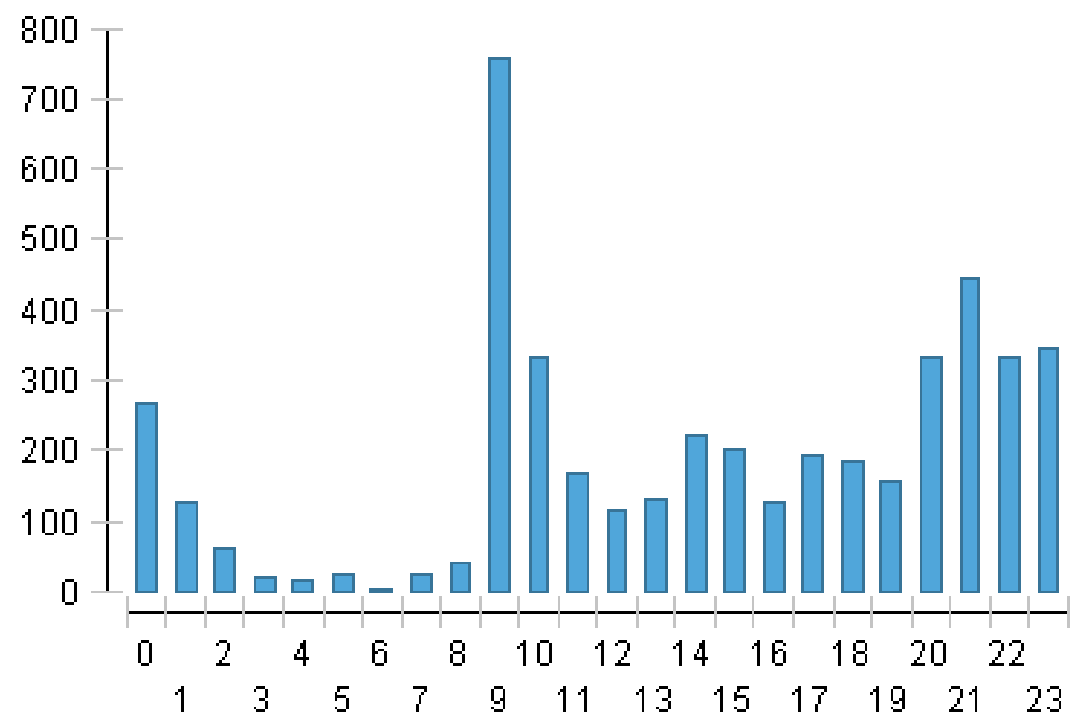

Figure 2: Time Spent on LMS according to the time of the day 
As can be seen in Figure 2, the students mostly spent time in the LMS at 9:00 am and 9:00 pm. The face-to face course started at 9:00 am and ended at 12:00 pm. Thus, the students mostly spent time on LMS at school in the first course hour and at home in the evening. Based on this finding, it could be stated that the students used the LMS to check the contents shared in the beginning of the lesson and to study the shared post-course contents at home.

Figure 3 represents the tools the students used in the LMS and the time they spent using these tools.

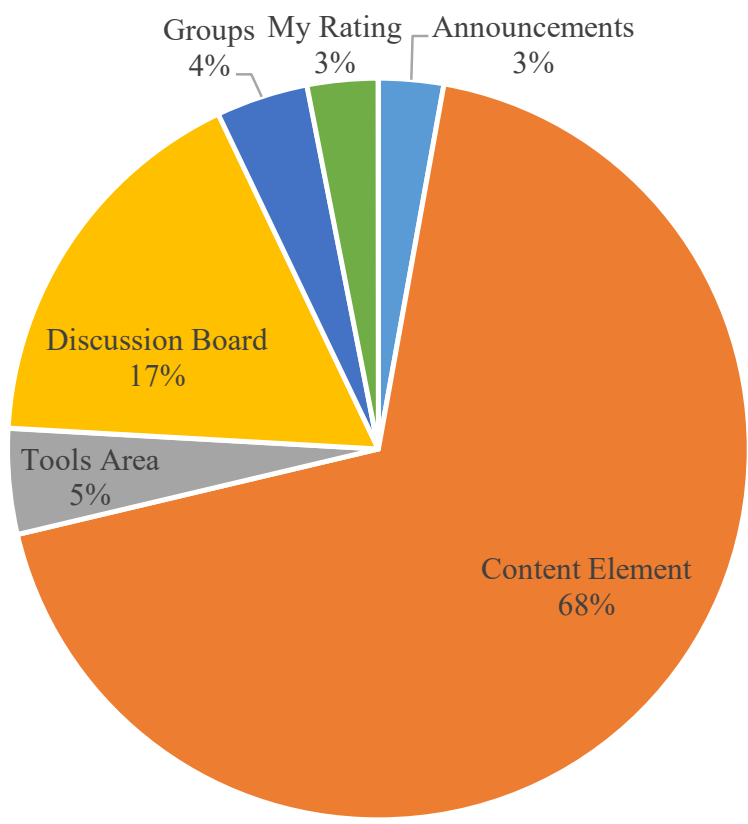

Figure 3: Percentages of LMS tool use

As can be seen in Figure 3, the students mostly used the content elements in the LMS. As the content elements were among those shared most within the scope of the lesson, it was an expected result that the students used the content elements most. This finding is similar to the results obtained in other studies in the related literature (Emelyanova \& Voronina, 2014).

\section{Relationship between Online Learning Behaviors and Academic Achievement}

In order to determine whether there was a significant relationship between the students' online learning behaviors and their academic achievement, a Pearson correlation coefficient was used. Table 1 below presents the correlation matrix between Grade Point Average (GPA) and online learning behaviors.

Table 1: Correlation matrix between online learning behaviors and academic achievement

\begin{tabular}{|c|c|c|c|}
\hline & Number of Login & Total time spent on LMS & Number of hit \\
\hline$\overline{\text { GPA }}$ & .140 & $.264 * *$ & .154 \\
\hline \multicolumn{4}{|c|}{$\mathrm{N}=71, * *$ Correlation is significant at the level of 0.01 (two-tailed) } \\
\hline
\end{tabular}


no statistically significant relationship was found between the students' GPAs and the number of $\operatorname{logins} /$ hits.

In order to determine whether the total time spent in the LMS predicted GPA, a simple linear regression analysis was conducted. The regression analysis showed that the total time spent by the students in the LMS predicted academic GPA positively and significantly $\left(F_{(1,69)}=5.18, \mathrm{p}=.026<.05\right.$, Adjusted $\left.R^{2}=.056\right)$. The simple scatterplot of these two variables can be seen in Figure 4 below.

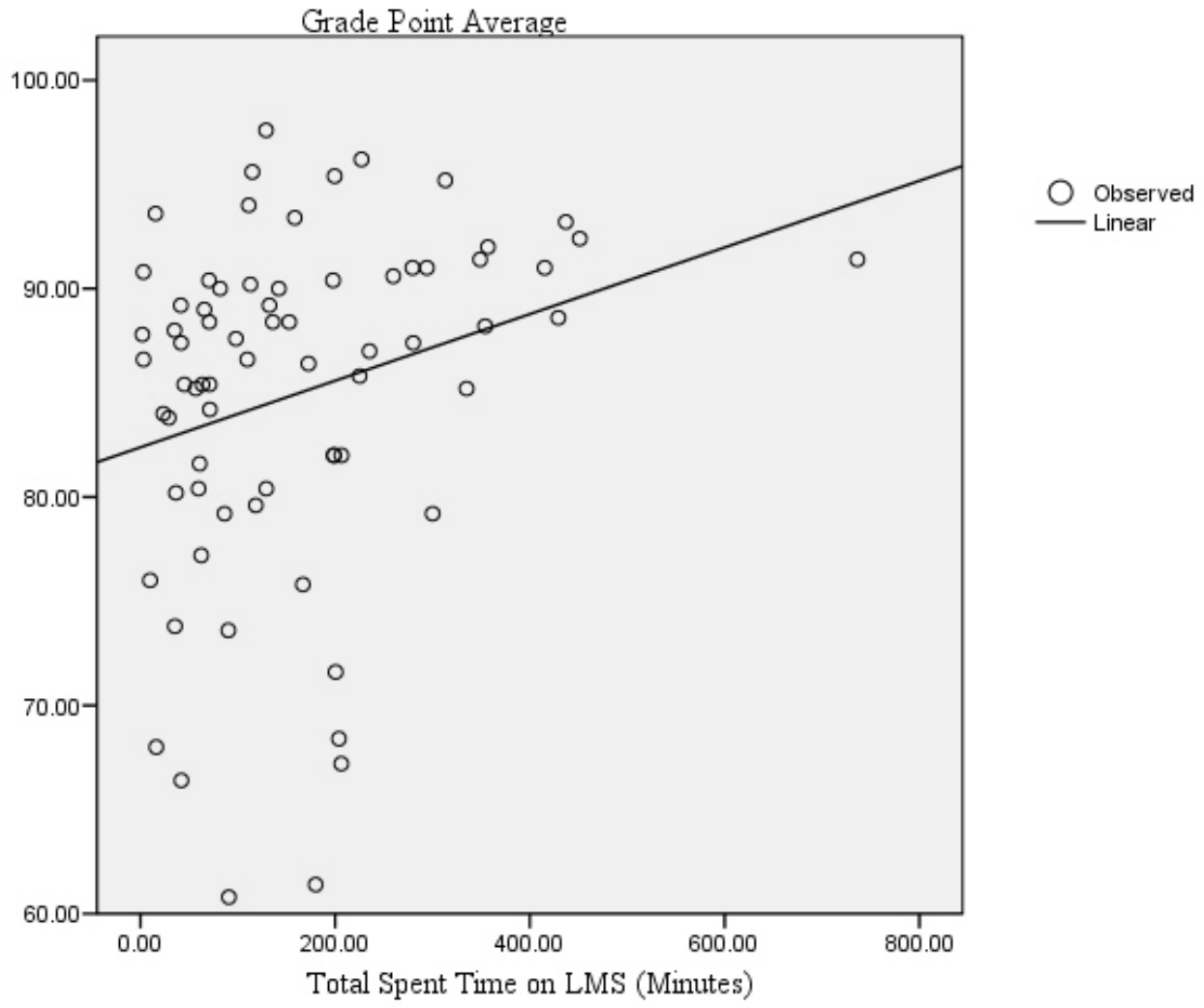

Figure 4: Scatterplot of total time spent on LMS and GPA

Regression weight is the non-standardized coefficient, and it refers to the $\beta=+.264$ unit increase in GPA score yielded by one unit the total spent time on LMS. Thus, a statistically significant and positive causal relationship was found between GPA and total time spent in the LMS. According to Castaño-Muñoz et al. (2014), the time spent by itself does not increase learning success; on the other hand, success increases only when interactive learning occurs within the time spent. In order to test this claim, the students' GPAs were ranked from higher to lower and divided into two. In this method, the students were divided into two groups: those with higher GPAs and those with lower GPAs. For the purpose of determining whether there was a significant difference between the groups with respect to the number of logins, the number of hits and the time they spent on LMS, independent samples t-test was applied. The results are presented in Table 2.

The results of the independent samples t-test revealed a significant difference regarding only the time the students spent on LMS with respect to their GPAs $\left[\mathrm{t}_{(69)}=2.957, \mathrm{p}<.001\right]$. This finding demonstrated that the students with higher GPA ( $\bar{X}=207$ minutes) spent significantly higher time in the LMS environment than those with lower GPA ( $\bar{X}=116$ minutes). This result supports the claim by Castaño-Muñoz et al. (2014) cited above. 
Table 2: Independent samples t-test regarding the students' technology scores with respect to their GPAs

\begin{tabular}{lllclll}
\hline & Groups & $\mathrm{N}$ & $\overline{\mathrm{X}}$ & $\mathrm{Sd}$ & $\mathrm{t}$ & $\mathrm{p}$ (2-way) \\
\hline Number of Login & Low GPA & 35 & 26.1944 & 16.879 & -.340 & .735 \\
& High GPA & 36 & 27.4286 & 13.423 & & \\
\hline Time Spent & Low GPA & 35 & 116.2069 & 86.743 & -2.957 & $.004^{*}$ \\
(Minutes) & High GPA & 36 & 207.2394 & 162.444 & & \\
\hline Hits & Low GPA & 35 & 37.6389 & 29.271 & -.594 & .555 \\
& High GPA & 36 & 41.6571 & 27.717 & & \\
& & & & & &
\end{tabular}

* There is a significant difference at the level of $\mathrm{p}<.001$.

\section{Students' Views about the Effects of LMSs on Academic Achievement}

The students' views were determined with the question, "Do you think Learning Management Systems like Blackboard used as a support environment during lessons influence academic achievement?" A total of 43 students responded to the question. However, nine of the responses to the question were not included in the analysis since they were found irrelevant to the question. Therefore, the remaining 34 responses were tabulated and coded as required by content analysis, and the sub-themes were obtained. The process of coding qualitative data and theme extraction coding and themes was run in parallel with the two doctorate academicians. In the end, themes were determined via the sub-themes. Table 3 presents the themes obtained via the students' views and the frequencies regarding the direction of their views.

Table 3: Themes obtained via the students' views and the direction of their views

\begin{tabular}{|c|c|c|}
\hline Category & Themes and Direction of Views & Frequency (f) \\
\hline \multirow[t]{6}{*}{ Themes } & Effective Use & 15 \\
\hline & Attractive Design & 7 \\
\hline & Interaction-Communication & 4 \\
\hline & Use for Reinforcement & 4 \\
\hline & Social Media Support & 2 \\
\hline & Accessibility & 2 \\
\hline \multirow{5}{*}{$\begin{array}{l}\text { Direction of } \\
\text { Views }\end{array}$} & LMSs have positive influence on academic achievement & 24 \\
\hline & $\begin{array}{l}\text { LMSs have positive influence on academic achievement or do } \\
\text { not have any influence }\end{array}$ & 4 \\
\hline & $\begin{array}{l}\text { LMSs have positive or negative influence on academic } \\
\text { achievement }\end{array}$ & 4 \\
\hline & LMSs do not have any influence on academic achievement & 1 \\
\hline & LMSs have negative influence on academic achievement & 1 \\
\hline
\end{tabular}


As can be seen in Table 3, the themes were obtained via the inductive analysis of the qualitative data collected from students' views. In addition, the direction of students' views about whether LMSs have influence on academic achievement or not was determined. The results of the analysis revealed that the theme supported by the students most was effective use. According to this theme, the students agreed that LMSs could increase academic achievement if used effectively. In relation to this, two students reported their views as follows:

"If used effectively and if the student or the teacher become active in the learning management system, then this may influence academic achievement positively." A6

"It could certainly be beneficial when it is used effectively." A2

After the theme of effective use, the other themes obtained via the students' views were attractive design, interaction-communication, use for reinforcement, social media support, and accessibility. Regarding each of these themes, a direct quotation from student views is provided below:

"LMS has influence on academic achievement, but I think it should be attractive enough for us to use it." A7

"Yes, it influences academic achievement because it allows the teacher and students to be in communication and interaction out of class." A4

"Lessons do not remain restricted with classes. We reinforce our learning thanks to LMS" A14

"No system that fails to work without being integrated into social media can engage the user. When students get informed about an assignment thanks to notification on Facebook, they can become successful" A25

"Only those who receive related services can benefit from the system, and those who do not receive such services can not keep up with their peers receiving these services" A20

As can be seen, the students believed that LMSs could influence academic achievement in only the following conditions: the system should be appropriate for effective use; should have an attractive design; should allow interaction; should support reinforcement; should provide social media support; and it should allow accessibility.

\section{Discussion}

The present study sought to determine the effects of undergraduate students' LMS learning behaviors on their academic achievement. In line with this purpose, the LMS dashboard analytics data produced by a total of 71 undergraduate students for a period of 14 weeks as a support to their face-to-face course, the GPAs they got for this course at the end of the academic term, and their views about the effects of LMSs on academic achievement were examined. Within the limitations of the study, the results of the analyses revealed several important findings. These findings are discussed below.

According to the findings obtained via the LMS analytics, the students spent more time in the LMS on face-to-face course days. In addition, it was found that the students spent more time in the LMS at the beginning of the lesson (to check the contents shared) and at night on the same day (to study the contents shared). Lastly, it was seen that the students mostly used content elements in the LMS. This finding supports the result obtained by Emelyanova and Voronina (2014), who reported that LMSs are regarded as storage for course materials and are used for this purpose.

The results of the Pearson correlation analysis conducted to determine the relationship between the students' behaviors in the LMS and their GPAs revealed no statistically significant relation- 
ship between the students' GPAs and number of logins and number of hits. This finding differs from the finding obtained by Jo et al. (2015), who claimed that "total logins to LMS had a significant correlation with final grades." As a result of linear regression analysis, a statistically significant and positive causal relationship was found between GPA and the total time spent in the LMS. This finding also differs from the finding obtained by Jo et al. (2015), who reported that "total study time in LMS did not predict final grades." Castaño-Muñoz et al. (2014) point out that time spent without any interaction will not increase learning success. In order to test this claim, the number of logins, number of hits, and the time spent by the students were compared with their GPA scores. For this purpose, an independent samples t-test was conducted, and the results revealed that the student GPAs differed significantly only with respect to the time they spent on LMS. This finding differs from the finding obtained by Castaño-Muñoz et al. (2014), who reported that the time spent did not influence achievement. Based on all these findings, it could be stated that the time spent in the LMS increases the GPA score. This may be due to the fact that students are likely to learn the subject subconsciously while surfing through the LMS (latent learning).

In the study, 34 students' views were analyzed to determine whether the LMS had influence on their academic achievement. The results revealed that almost all of the students believed LMSs could increase academic achievement. In addition, it was pointed out by the students that LMSs should have certain features to increase academic achievement. As a result of the inductive content analysis, it was found that LMSs should have six features to increase academic achievement. These features are presented in Figure 5. To make it easier to read the paper online, use single column formatting for the paper.

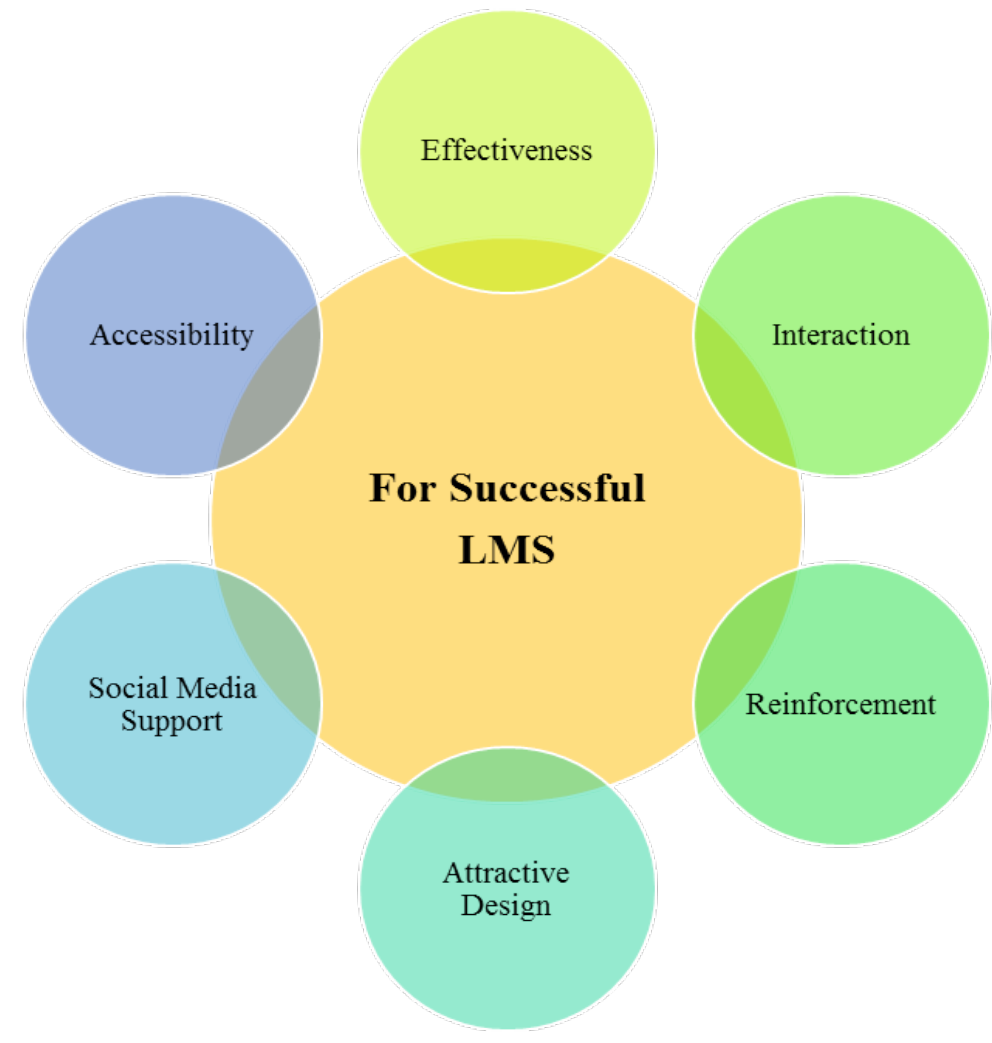

Figure 5: Expected features of LMSs

Based on students' views, as can be seen in Figure 5, six basic features that LMSs should have to increase academic achievement were determined. It is important that these features are formed by information technology preservice teachers who use LMSs actively and who have background 
knowledge about Information Technologies as required by their field. The reason is that preservice teachers from the Department of Computer Education and Information Technologies, part of the research sample, basically focus on technology use in education.

\section{Conclusions and Suggestions}

Not only making predictions in relation to learning in electronic environments but also providing learners with effective feedback are regarded as the most important outcomes of learning analytics. LMSs, which are commonly used to support online learning as well as face-to-face learning, can provide comprehensive research opportunities for learning analytics by keeping detailed records of user behavior data. However, there is little research in the related literature, backed by student views and utilizing learning analytics, inquiring into the effects of LMSs on academic achievement. Therefore, in the present explanatory mixed-method research, the purpose was to determine the effects of students' LMS learning behaviors on their academic achievement.

In line with the basic purpose of the study, the findings obtained via the analyses conducted with the help of learning analytics revealed several important results that could be beneficial both for practical implications and future research implications. First of all, the students used LMSs as a support for their face-to-face education on face-to-face course days. Considering this result, trainers and web-designers could increase interaction during these periods. In addition, the students mostly interacted with content elements in LMS. Based on this result, the quality of the content components shared in LMSs and the active use of other components could be increased.

For the purpose of determining the effects of the students' LMS learning behaviors on their academic achievement, parametric tests were used in the study. In addition, given the limitations of the study, no significant relationship was found between the students' academic achievement and the number of total login/total hit; however, a significant positive relationship was found between the time students spent on LMS and their academic achievement. This finding is thought to result from latent learning.

\section{Implications}

Based on the results, several practical suggestions could be put forward: First of all, effective use of LMSs is necessary to support students' academic achievement. In addition, with the help of attractive applications and content, trainers could contribute to their students' academic achievement by increasing the time students spend on LMSs.

Based on the views of students, it could be stated that LMSs can increase academic achievement providing that they have certain features. These features were identified to be Effectiveness, Interaction, Reinforcement, Attractive Design, Social Media Support, and Accessibility. In this respect, whether they are used as a basic learning environment or as a support environment, LMSs could be used in line with the features determined in the present study so that they can have positive influence on student achievement. Also, it is suggested that LMS developers and designers should revise and enrich their systems. As a basic and supplementary learning environment, a LMS has quite a large area of use; thus, the implications of this study are thought to be fairly important.

\section{Limitations and Future Research}

To understand the results obtained in the present study better, it is important to determine its limitations. This study is limited to the 71 third-year students taking the course of BTÖ311 Operating Systems in the Department of Computer Education and Instructional Technologies at the Education Faculty of Anadolu University in the Fall Term of the academic year of 2014-2015, to the 
Blackboard learning management system, to the log reports provided by this learning environment for the 14-week course, and to the views of 34 students.

In the future, more comprehensive studies could be conducted with larger populations and variables using other components of learning analytics such as social network, data mining, and data visualization. These studies could investigate the effects of LMSs on engagement, motivation, and drop-out rate besides learning achievement. In addition, other studies could examine the effects of support provided in LMSs such as social Web, interaction, and academic achievement consolidation.

\section{References}

Agudo-Peregrina, Á. F., Iglesias-Pradas, S., Conde-González, M. Á., \& Hernández-García, Á. (2014). Can we predict success from log data in VLEs? Classification of interactions for learning analytics and their relation with performance in VLE-supported F2F and online learning. Computers in Human Behavior, 31, 542-550.

Arnold, K. E., \& Pistilli, M. D. (2012, April). Course signals at Purdue: Using learning analytics to increase student success. In Proceedings of the 2nd International Conference on Learning Analytics and Knowledge (pp. 267-270). ACM.

Blikstein, P. (2011, February). Using learning analytics to assess students' behavior in open-ended programming tasks. In Proceedings of the 1st International Conference on Learning Analytics and Knowledge (pp. 110-116). ACM.

Breslow, L., Pritchard, D. E., DeBoer, J., Stump, G. S., Ho, A. D., \& Seaton, D. T. (2013). Studying learning in the worldwide classroom: Research into edX's first MOOC. Research \& Practice in Assessment, $8(1), 13-25$.

Castaño-Muñoz, J., Duart, J. M. \& Sancho-Vinuesa, T. (2014). The Internet in face-to-face higher education: Can interactive learning improve academic achievement? British Journal of Educational Technology, 45(1), 149-159.

Conde, M. Á., \& Hernández-García, Á. (2015). Learning analytics for educational decision making. Computers in Human Behavior, 47, 1-3. doi:10.1016/j.chb.2014.12.034

Creswell, J. W. (2008). Educational research planning, conducting and evaluating quantitative and qualitative research. International Pearson Merril Prentice Hall.

Creswell, J. W., \& Plano Clark, V. L. (2011). Designing and conducting mixed methods research. Thousand Oaks, CA: Sage Publications, Inc.

Elias, T. (2011). Learning analytics: Definitions, processes and potential. Retrieved February 15, 2014, from http://learninganalytics.net

Emelyanova, N., \& Voronina, E. (2014). Introducing a learning management system at a Russian university: Students' and teachers' perceptions. The International Review of Research in Open and Distributed Learning, 15(1).

Gašević, D., Dawson, S., \& Siemens, G. (2015). Let's not forget: Learning analytics are about learning. TechTrends, 59(1), 64-71.

Holland, C., \& Muilenburg, L. (2011, March). Supporting student collaboration: Edmodo in the classroom. In Society for Information Technology \& Teacher Education International Conference (Vol. 2011, No. 1, pp. 3232-3236).

Jo, I. H., Yu, T., Lee, H., \& Kim, Y. (2015). Relations between student online learning behavior and academic achievement in higher education: A learning analytics approach. In G. Chen, V. Kumar, Kinshuk, R. Huang, \& S. C. Kong (Eds.), Emerging issues in smart learning (pp. 275-287). Springer Berlin Heidelberg. 
Johnson, L., Adams Becker, S., Estrada, V. \& Freeman, A. (2014). NMC Horizon Report: 2014 Higher Education Edition. Austin, Texas: The New Media Consortium.

Macfadyen, L. P., \& Dawson, S. (2010). Mining LMS data to develop an "early warning system" for educators: A proof of concept. Computers \& Education, 54(2), 588-599.

Osgood, C. E., Suci, G. J., \& Tannenbaum, P. H. (1957). The measurement of meaning. Urbana: University of Illinois Press.

Shum, S. B., Knight, S., \& Littleton, K. (2012). Learning analytics. In UNESCO Institute for Information Technologies in Education. Policy Brief.

Siemens, G. (2013). Learning analytics: The emergence of a discipline. American Behavioral Scientist, 57(10), 1380-1400.

Stantchev, V., Colomo-Palacios, R., Soto-Acosta, P., \& Misra, S. (2014). Learning management systems and cloud file hosting services: A study on students' acceptance. Computers in Human Behavior, 31, 612-619.

\section{Biography}

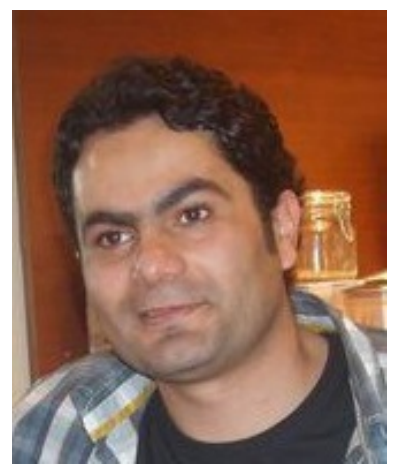

Dr. Mehmet FIRAT is an Assistant Professor in the Department of Distance Education, Open Education Faculty at the Anadolu University, Turkey. He has a PhD in Educational Technology. Dr. FIRAT is also deputy head of the Distance Education Department. His academic interest areas are open and distance education, distance education technologies, educational hypermedia and multimedia, educational interfaces, metaphorical interface designs, e-learning, cyber behaviors, PLE systems, instructional design. Dr. FIRAT has over than 30 articles published in international and national journals, international book chapters and papers submitted to international meetings. 